\title{
X. The ionic and thermal coefficients of nitric acid
}

\author{
V.H. Veley D.Sc. F.R.S. \& J.J. Manley
}

To cite this article: V.H. Veley D.Sc. F.R.S. \&J.J. Manley (1902) X. The ionic and thermal coefficients of nitric acid, Philosophical Magazine Series 6, 3:13, 118-122, DOI: 10.1080/14786440209462743

To link to this article: http://dx.doi.org/10.1080/14786440209462743

$$
\text { 曲 Published online: } 09 \text { Jun } 2010 .
$$

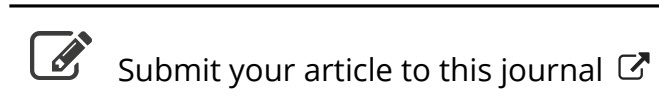

\section{Џll Article views: 2}

\section{Q View related articles $\square$}

Citing articles: 1 View citing articles 5 


\section{$\left[\begin{array}{ll}118 & ]\end{array}\right.$}

X. The Ionic and Thermal Coefficients of Nitric Acid. By V. H. Vet.ey, D.Sc., F.R.S., and J. J. Manley, Daubeny Curator, Magdalen College, Orford* .

TN a former investigation + we have published determinations 1 of the electric conductivity of nitric acid of different concentrations at the three temperatures $0^{\circ}, 15^{\circ}$, and $30^{\circ} \mathrm{C}$. obtained by the method of Kohlrausch with certain modifications. It has for some time been noted that the strong mineral acids do not follow Ostwald's dilution law

$$
\frac{\mu^{2}}{\left(\mu_{\infty}-\mu\right) V \mu_{\infty}}=\mathrm{K} \text {; . . . . . }
$$

and though the results obtained are more in accordance with the Rudolphi-van't Hoff $\ddagger$ equation

$$
\frac{\alpha^{3}}{(1-\alpha)^{2} \mathrm{~V}}=\mathrm{K}, \alpha=\frac{\mu}{\mu_{\infty}}, \quad \text {. . . . . }
$$

yet the relation can only be regarded as empirical.

It seemed, therefore, of interest to calculate from our conductivity determinations the amount of ionization $\frac{\mu}{\mu_{\infty}}$-at the different percentage concentrations ; for though results for dilute samples have been given by Kohlrausch $\S$ and others, yet no data have been published for more concentrated samples. The value for the molecular conductivity at infinite dilution or $\mu_{\infty}=\mathrm{K} 10^{7}$, according to the data of Koblrausch is $\mathrm{K}_{18}=342$, or $\mathrm{K}_{15}=325 \cdot 4$ when reduced by the formula

$$
\mu_{15}=\mu_{18} 342(1+\cdot 0162[15-18]) \text {. . . . }
$$

In the following Table values are given : in column $I$. the percentage concentration, in II. the corresponding molecular dilution, in III. the values for $\mu \times 10^{7}$, and in IV. the values for $\frac{\mu}{\mu_{\infty}}$, the quotient of ionization.

It will be observed that there is an irregularity in the results for the samples from 98 per cent. to 100 per cent., which is consequent upon a reversal in the conductivity values; and in our work mentioned above attention was drawn not only to this point, but also that whereas nitric acid bebaves

* Communicated by the Authors.

† Phil. Trans. 1898, A. p. 365.

Teits.f.physikal. Chem. xvii. p. 385 (1895), and xviii. p. 301 (1895).

$\S$ Wied. Ann. xxvi. p. 196 (1885). 
as other electrolytes in possessing a positive temperaturecoefticient for concentrations up to 96 per cent., yet beyond this point it behaves as a metallic conductor in possessing a negative temperature-coefficient.

TABLE I.

\begin{tabular}{|c|c|c|c|}
\hline $\begin{array}{l}\text { Percentage } \\
\text { Proportion. }\end{array}$ & $\begin{array}{l}\text { Molecular } \\
\text { Dilution. }\end{array}$ & $\begin{array}{c}\mu_{15} \\
\text { in mercury } \\
\text { units } \times 10^{\frac{5}{5}} \text {. }\end{array}$ & $\frac{\mu_{15}}{\mu_{15 \infty}}$ \\
\hline $\begin{array}{c}1 \cdot 30 \\
3 \cdot 12 \\
5 \cdot 99 \\
10 \cdot 13 \\
15 \cdot 32 \\
20 \cdot 11 \\
25 \cdot 96 \\
30 \cdot 42 \\
33 \cdot 81 \\
35 \cdot 90 \\
39 \cdot 48 \\
45 \cdot 01 \\
51 \cdot 78 \\
53 \cdot 03 \\
58 \cdot 20 \\
61 \cdot 20 \\
65 \cdot 77 \\
69 \cdot 53 \\
73 \cdot 82 \\
76 \cdot 59 \\
78 \cdot 90 \\
84 \cdot 08 \\
86 \cdot 18 \\
87 \cdot 72 \\
89 \cdot 92 \\
91 \cdot 87 \\
94 \cdot 32 \\
96 \cdot 12 \\
98 \cdot 50 \\
98 \cdot 85 \\
99 \cdot 27 \\
99 \cdot 97\end{array}$ & $\begin{array}{l}4 \cdot 568 \\
1 \cdot 956 \\
1 \cdot 164 \\
0 \cdot 559 \\
0 \cdot 349 \\
0 \cdot 251 \\
0 \cdot 180 \\
0 \cdot 144 \\
0 \cdot 123 \\
0 \cdot 112 \\
0 \cdot 096 \\
0 \cdot 077 \\
0 \cdot 059 \\
0 \cdot 056 \\
0 \cdot 045 \\
0 \cdot 040 \\
0 \cdot 032 \\
0 \cdot 028 \\
0 \cdot 022 \\
0 \cdot 019 \\
0 \cdot 017 \\
0 \cdot 012 \\
0 \cdot 010 \\
0 \cdot 007 \\
0 \cdot 007 \\
0 \cdot 006 \\
0 \cdot 004 \\
0 \cdot 002 \\
0 \cdot 001 \\
0 \cdot 001 \\
0 \cdot 001 \\
0\end{array}$ & $\begin{array}{c}288 \cdot 0 \\
281 \cdot 5 \\
258 \cdot 9 \\
228 \cdot 0 \\
190 \cdot 1 \\
159 \cdot 3 \\
123 \cdot 5 \\
100 \cdot 1 \\
85 \cdot 8 \\
73 \cdot 6 \\
63 \cdot 8 \\
47 \cdot 9 \\
32 \cdot 6 \\
30 \cdot 4 \\
22 \cdot 2 \\
18 \cdot 6 \\
13 \cdot 3 \\
10 \cdot 3 \\
6.43 \\
5 \cdot 03 \\
3.27 \\
1 \cdot 09 \\
0.94 \\
0.62 \\
0.36 \\
0.17 \\
0.07 \\
0.035 \\
0.016 \\
0.013 \\
0.017 \\
0.007\end{array}$ & $\begin{array}{l}0 \cdot 885 \\
0 \cdot 865 \\
0 \cdot 796 \\
0 \cdot 701 \\
0.571 \\
0 \cdot 487 \\
0.379 \\
0 \cdot 308 \\
0 \cdot 263 \\
0 \cdot 226 \\
0 \cdot 196 \\
0 \cdot 117 \\
0 \cdot 102 \\
0.093 \\
0.086 \\
0 \cdot 057 \\
0 \cdot 041 \\
0 \cdot 032 \\
0.020 \\
0 \cdot 015 \\
0.010 \\
0.004 \\
0 \cdot 003 \\
0 \cdot 002 \\
0 \cdot 001 \\
0 \cdot 0005 \\
0 \cdot 0002 \\
0 \cdot 0001 \\
0 \cdot 00005 \\
0 \cdot 00004 \\
0 \cdot 00005 \\
0 \cdot 00002\end{array}$ \\
\hline
\end{tabular}

It is evident that this phenomenon cannot be explained by the aid of the ionic dissociation theory, as the number of free ions would not exceed four per 1000. As we have observed a similar abuormality in other physical properties, and especially in the contractions as calculated from the density determinations, we consider it probable that the result is due to an incipient formation of the compound $2 \mathrm{HNO}_{3} . \mathrm{N}_{2} \mathrm{O}_{5}$, which is prepared by dissolving nitrogen pentoxide in anhydrous nitric acid. 
The values for $\mu$ for the acids of lower percentage concentration ( 1 per cent. to 42 per cent.) are generally somewhat lower than those given by Kohlrausch; but those for $\frac{\mu}{\mu_{\infty}}$ are more in accordance with those calculated by Jones $*$ from the freezing-point determinations.

Kohlrausch and Hallwachs $\dagger$ have pointed out that there is an undoubted relation between the contraction, produced even in very dilute solutions of electrolytes, and ionic dissociation, since non-electrolytes do not show this phenomenon. In the present instance, though the points of alteration of direction of curvature are the same both for the contractions and the quotient of ionic dissociation, if expressed in terms of percentages, yet correlation of the two phenomena does not appear to be of a simple character.

\section{Coefficients of Expansion.}

Very few data of the coefficients of expansion of nitric acid have as yet been recorded. Kobl $\ddagger$, many years ago as a result of his density determinations, observes as follows :"Le coéfficient de la dilatation de l'acide azotique est assez élevé. Ainsi pour l'acide azotique monohydrate, le coéfficient moyen de dilatation entre 0 degré et 15 degrés est $a=\cdot 001263$, c'est à dire environs trois fois plus fort que celui de l'eau."

Marignac gave values for the constants $a, b$, and $c$ in the equation

$$
\mathrm{V}_{t}=\mathrm{V}_{0}\left(1+a t+b t^{2}+c t^{3}\right) \text {. . . . . }
$$

for a few samples; and lastly Lunge and Rey $\S$ published the corrections of densities at $15^{\circ}$ for temperatures between $13^{\circ}$ and $17^{\circ}$, in all seventeen values. From our density determinations at $4^{\circ}, 14^{\circ} \cdot 2$, and $24^{\circ} \cdot 2$ corrected to a vacuum we have calculated the values for the mean cubic expansion or values of $a$ from the equation

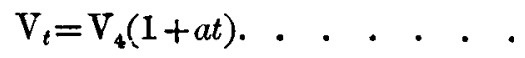

These values expressed as $\alpha \times 10^{-6}$ are given in the following table.

* Zeits.f. physikal. Chem. xii. p. 623 (1893).

+ Göttingen Nachrichten, 1893, pp. 350-357. Cf. Drude and Nernst, Zeits. f. physikal. Chem. xv. p. 79 (1894).

I Ann. Chim. Phys. [4] x. p. 140.

\$eits. f. angew. Chemie, 1891, p. 167, and 1892, p. 10. 
Ionic and Thermal Coefficients of Nitric Acid.

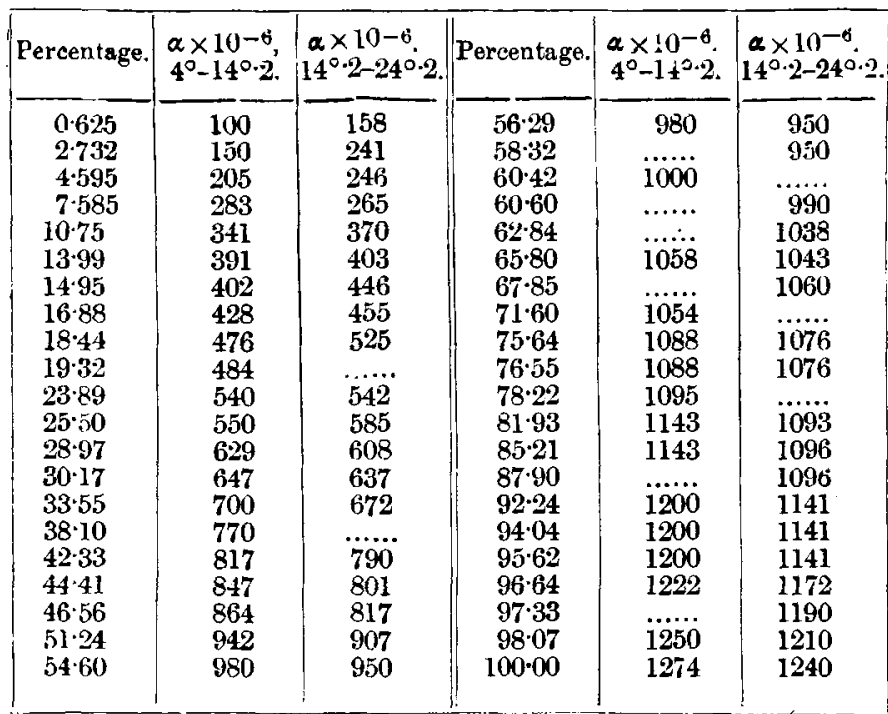

The value obtained for the 100-per-cent. acid for the temperature-limit $4^{\circ}-14^{\circ}$, namely 001274 , approximates very closely to that obtained by Kolb, namely 001263 between the limits $0^{\circ}-15^{\circ}$; but it appears that he made an arithmetical mistake in referring to the value as about three times as great as the mean coefficient of water between the same limits; this latter, according to Rosetti's tables, is $\cdot 000047$, so that the value for nitric acid is nearly thirty times as great (actually $27 \cdot 1$ ).

The above results show that as regards the mean coefficient of expansion, nitric acid of different concentrations does not behave as if it were a mere mixture of the acid and water.

The following selected values illustrate this point :-

$\begin{array}{ccc}\text { Percentage. } & \begin{array}{c}\text { Sum of Coefficients } \\ \text { calculated at } 4^{\circ}-14^{\circ} \cdot 2 .\end{array} & \begin{array}{c}\text { Coefficient found } \\ \text { at } 4^{\circ}-14^{\circ} \cdot 2 .\end{array} \\ 10^{\circ} 75 & 180 \times 10^{-6} & 341 \times 10^{-6} \\ 30.17 & 417 \times 10^{-6} & 647 \times 10^{-6} \\ 51.24 & 676 \times 10^{-6} & 942 \times 10^{-6} \\ 75.64 & 978 \times 10^{-6} & 1088 \times 10^{-6} \\ 94.04 & 1126 \times 10^{-6} & 1200 \times 10^{-6}\end{array}$

In every case the found value exceeds that calculated, though the difference decreases as the percentage-concentration increases.

Though there seems to be no simple relation between the 
ratios of the calculated and found coefficients of expansion, on the one hand, and the factor of ionic dissociation, on the other, yet such a general result as that given above would follow if the sums of the coefficients of expansion of the separated ions, namely, $\widehat{\mathrm{H}}$ and $\widehat{\mathrm{NO}}_{3}$, were greater than that of the undissociated molecule $\mathrm{HNO}_{3}$. The general result is, however, probably complicated by the affinity of the acid for water and the consequent formation of either hydrates or of complex molecular structures (say $x$ ), each of which would have its particular coefficient. The net result is expressible by a general equation :

$$
\mathrm{K}=\mathbf{\Sigma}\left[k\left(\mathrm{H}_{1}\right)+k^{\prime}\left(\mathrm{NO}_{3}\right)+k^{\prime \prime}\left(\mathrm{HNO}_{3}\right)+k^{\prime \prime \prime}(x) \ldots\right] .
$$

A further point of interest is that the values for the lower temperature-limit are for the lower percentage concentrations less than the values for the higher temperature-limit, yet for the higher percentage concentration this relation is reversed; the reversal takes place at about 40 per cent.

If a curve be drawn in which the mean coefficients for either limits of temperature are expressed in terms of percentages, the observational results are found to lie approximately upon four straight lines-namely, firstly, from 1 to 8 per cent.; secondly, from 11 to 54 per cent.; thirdly, from 54 to 70 per cent. ; and, fourthly, from 70 to 93 per cent.; and the remainder upon an irregular curve.

With regard to these several points, it may be noticed that the 54 per cent. corresponds to that of maximum contraction as found by Kolb and ourselves, while the irregularity from 92 to 100 per cent. has already been alluded to. The behaviour of nitric acid as regards this physical property is so far different from sulphuric acid, which has been completely investigated by Pickering*, in that, firstly, the variations are much more marked; and, secondly, the maximum value occurs at 100 per cent., while that of sulphuric acid is at about 86 per cent., from which point the value of the coefficient decreases to 98 per cent., and from this concentration up to 100 per cent. slightly increases.

In conclusion, we trust that we may be allowed to raise a plea for the more complete investigation of the physical properties of solutions of liquids in liquids of a high degree of concentration as regards the solute. The results to be obtained will, we believe, be as full of interest as those already obtained with solutions of a high degree of dilution as regards the solvent water.

Oxford, October 1901.

$$
\text { * Journ. Chem. Soc. 1890, p. } 114 .
$$

